\title{
UCLA
}

Mester

Title

Disco Disco

Permalink

https://escholarship.org/uc/item/34f4p582

Journal

Mester, 20(1)

Author

Mester, [No author]

Publication Date

1991

DOI

10.5070/M3201014133

Copyright Information

Copyright 1991 by the author(s). All rights reserved unless otherwise indicated. Contact the author(s) for any necessary permissions. Learn more at https://escholarship.org/terms

Peer reviewed 


\section{Disco Disco}

En la continua búsqueda

En el estado de la música de disco

Me encuentro

Como Gloria Gaynor

En noches de Flamingo

Y palmeras de twelve west

Te busco

Entre poppers y notas de Flash

Gordon

Remuevo

Bíceps, nalgas, hombros, $\mathrm{T}$ shirts

recortadas

Restriego

Vueltas brazos muslos

Giro

Giro

Toda una noche

$\mathrm{Y}$ en taxi acompañado de pan de Zitos

Corremos a preparar el brunch

Despedida de Weekend

Hola.

Ernesto? 